\title{
Reactions with the Arylhydrazones of $\alpha$-Cyanoketones: Utility of Arylhydrazonomesoxalonitriles for the Synthesis of Azoles and Azolines
}

\author{
Ebtisam Abdel Aziz Hafez*, Mohamed Ali Elsayed Khalifa, Sayed Kamel Ahmed Guda, \\ and Mohamed Hilmy Elnagdi \\ Department of Chemistry, Faculty of Science, Cairo University, Giza, A. R. Egypt \\ Z. Naturforsch. 35 b, 485-489 (1980); received February 13/July 30, 1979 \\ Arylhydrazones, $\alpha$-Cyanoketones \\ The arylhydrazonomesoxalonitriles derivatives 1 a-c were utilised for the synthesis of \\ several new pyrimidine, pyridines, triazine and isoxazole derivatives. \\ Compound $\mathbf{1}$ a reacted with alkyl halides to yield the $\mathrm{N}$-alkyl derivatives $\mathbf{1 2} \mathbf{a}, \mathbf{b}$. The \\ latter reacted with hydrazines to yield the amidrazones $13 \mathbf{a}, \mathbf{b}$.
}

The coupling reaction of aryldiazonium salts with malononitriles has been reported to afford arylhydrazonomesoxalonitrile [1]. Although the activity of these compounds as oxidative phosphorylation inhibitors [2-5] has recieved considerable attention, only very little emphasis was placed on the chemical reactivity of this class of compounds [6,7]. In previous work, from this laboratory we have demonstrated the usefullness of these products as precorsures for synthesis of 3,5-diaminopyrazole derivatives [8-10]. In continuation of previous work we report here the results of our investigations aiming to explore the potential utility of these derivatives as intermediates in heterocyclic synthesis.

1 a reacts with thiourea to yield the diaminopyrimidine derivative 2. Compound $2\left(\mathrm{Ar}=\mathrm{C}_{6} \mathrm{H}_{5}\right)$ was converted into the aminopyrimidine hydrochloride (3a) on treatment with acetic acid-hydrochloric acid. Similar to $\mathbf{1}$ a, compound $\mathbf{1 b}$ reacted with thiourea to yield a product which on boiling for a short period with acetic acid-hydrochloric acid, afforded the hydrochloride $\mathbf{3} \mathbf{b}$.

Compound 1a reacted with urea to yield a product which could be converted into the hydrochloride 4 on treatment with acetic acid-hydrochloric acid mixture.

Compounds 1a-e, reacted with malononitriles to yield products for which structures 5 or possible isomeric 6 seemed possible on the basis of analytical and spectral data. In order to establish the structure of the product obtained by the reaction of $\mathbf{1}$ with

* Reprint requests to Dr. E. A. A. Hafez. 0340-5087/80/0400-0485/\$01.00/0 malononitrile, 2-amino-1,1,3-tricyanopropene was coupled with benzene diazonium chloride to afford a product which was considered to have structure 6 . The latter when boiled for a short period in DMF afforded a product identical in all respects with the product of reaction of $1 \mathrm{a}$ with malononitrile thus establishing structure 5 for the latter product [11].

The IR spectra of $\mathbf{5} \mathbf{a}, \mathbf{b}$ revealed a broad $\mathrm{CN}$ absorption in the region $2180-2200 \mathrm{~cm}^{-1}$ this large frequency shift may be attributed to the presence of amino and imino groups adjacent to the cyano function. Baldwin [12] has reported CN absorption for $\mathrm{O}$-aminonitriles in the range $2160-2200 \mathrm{~cm}^{-1}$.

Compounds Ia, b reacted with benzoyl isothiocyanate or with ethoxycarbonyl isothiocyanate to yield the amino-1,2,4-triazine derivatives $7 \mathbf{a}, \mathbf{b}$. When Ic was similarly treated, the amide 7 was the only isolable product. The formation of $7 \mathbf{a}, \mathbf{b}$ from the reaction of $\mathrm{Ia}, \mathrm{c}$ with isothiocyanates might be assumed to proceed via addition of the reagent to the hydrazone nitrogen to form the intermediate thiourea derivative 9. The latter the ncyclises into the triazine derivative 10 which losses a benzoyl or ethoxycarbonyl isothiocyanate to yield the final isolable $\mathbf{7 a}, \mathbf{b}$. In reaction with Ib, a longer reflux time was needed for complete reaction and it seems that traces of moisture in the reaction medium effects partial hydrolysis of the cyano group to yield the amide. The formation of 4-amino-1-aryl-1,2,4-triazines in this reaction may be considered as a new simple route for the synthesis of 1-aryl-4-amino-1,2,4-triazin-6-thione [13].

Compound 1 a reacted with hydroxylamine hydrochloride in the presence of sodium carbonate to 
yield a product, the analytical data of which indicated a molecular formula of $\mathrm{C}_{9} \mathrm{H}_{8} \mathrm{O}_{2} \mathrm{~N}_{4}$, two structures seemed possible for this product (cf. 11 and 12). Since the reaction product was found different from the known 12 [14], structure 11 was considered most likely for this product.

In previous work [9] from this laboratory it was been shown that arylazomesoxalonitrile reacts with diazomethane to yield N-methyl derivatives. Now it has been found that 1 a reacts similarly to yield 13 . Compound 13 a could also be obtained in better yield via alkylation of $\mathbf{1}$ a with methyl iodide in the presence of anhydrous potassium carbonate. The product in this case proved to be also free from

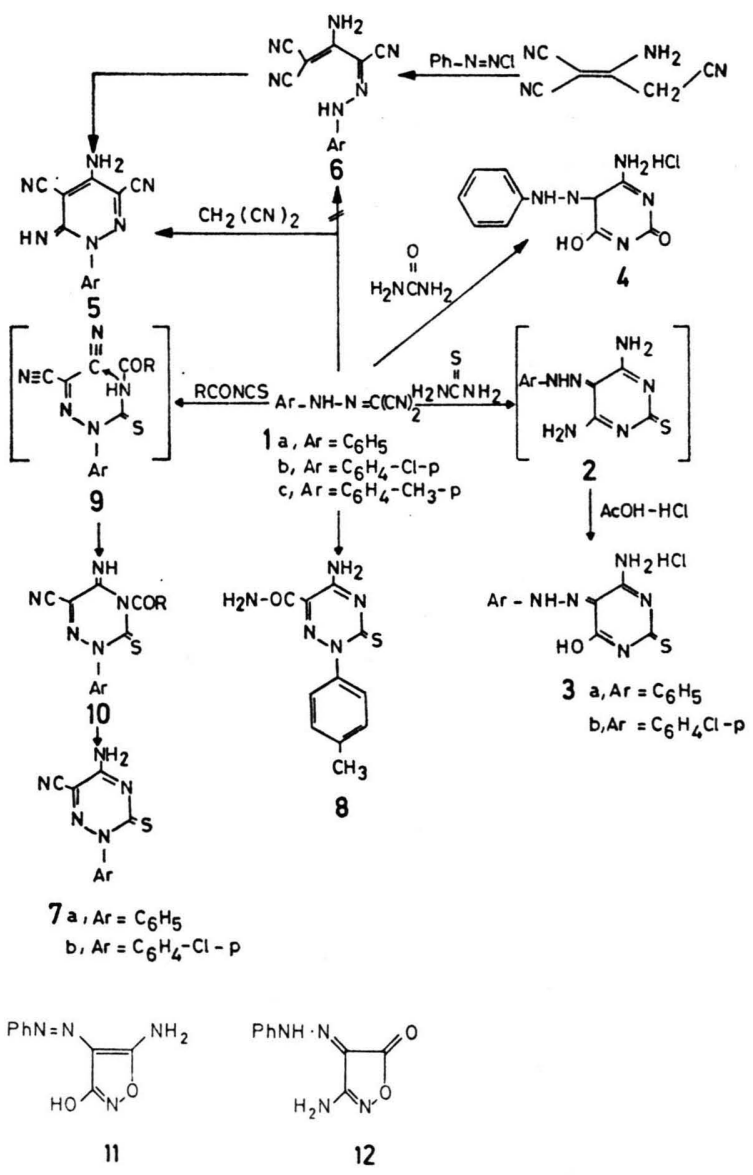

minor side reaction products always formed in the reaction with diazomethane. Similar to its behaviour towards methyl iodide, compounds $\mathbf{1} \mathbf{a}, \mathbf{b}$ reacted with ethyl iodide to yield the $\mathrm{N}$-ethyl derivatives $13 \mathrm{~b}, \mathrm{e}$.
The behaviour of 13a-c toward the action of hydrazine hydrate has also been investigated with the aim to obtain 4-N-alkylphenylhydrazono-3,5diaminopyrazoles (13). However in contrast to the behaviour of 1 , compounds 13 a-c reacted with hydrazine hydrate to yield only the amidrazones 14a-c. The latter could not be cyclized under a variety of conditions.

Thus, when refluxed in pyridine or in dry acetone compounds 13a- $g$, one molecule of hydrazine was eliminated and compounds $13 \mathbf{a}, \mathbf{b}$ were reformed in almost quantitative yield. Refluxing 14a in acetic acid offered a product for which structure 15 seemed most likely based on elemental and IR data under other cyclization conditions, mixtures of products were formed but non of which could be either isolated in pure form or could be identified.

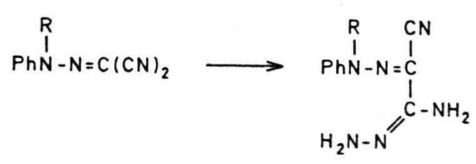

13a: $\mathrm{Ar}=\mathrm{C}_{6} \mathrm{H}_{5} ; \mathrm{R}=\mathrm{CH}_{3}$;

13b: $\mathrm{Ar}=\mathrm{C}_{6} \mathrm{H}_{5} ; \mathrm{R}=\mathrm{C}_{2} \mathrm{H}_{5}$;

13c: $\mathrm{Ar}=\mathrm{C}_{6} \mathrm{H}_{4} \mathrm{Cl}-\mathrm{p} ; \mathrm{R}=\mathrm{C}_{2} \mathrm{H}_{5}$.

14a: $\mathrm{Ar}=\mathrm{C}_{6} \mathrm{H}_{5} ; \mathrm{R}=\mathrm{C}_{2} \mathrm{H}_{5}$;

14b: $\mathrm{Ar}=\mathrm{C}_{6} \mathrm{H}_{5} ; \mathrm{R}=\mathrm{C}_{6} \mathrm{H}_{5}$;

14c: $\mathrm{Ar}=\mathrm{C}_{6} \mathrm{H}_{4} \mathrm{Cl}-\mathrm{p} ; \mathrm{R}=\mathrm{C}_{2} \mathrm{H}_{5}$.<smiles>CC(N)C1NNC(N(C)NN(C)c2ccccc2)C1NN(C)c1ccccc1</smiles>

15

Experimental

All melting points are uncorrected. IR spectra were recorded on a pye-unicam SP-1000 spectrophotometer. Analytical data were performed in the analytical data unit.

4-Amino-6-hydroxy-5-arylhydrazones2,5-dihydropyrimidine-2-thione hydrochlorides $(\mathbf{2} \mathbf{a}, \mathbf{b})$

To a solution of sodium ethoxide (prepared from $5.0 \mathrm{~g}$ of sodium metal and $150 \mathrm{ml}$ ethanol), compound $1 \mathrm{a}(0.01 \mathrm{~mole})$, and thiourea $(0.1 \mathrm{~mole})$ was added. The reaction mixture was refluxed for $10 \mathrm{~h}$, then evaporated in vacuo. The remaining product was dissolved in water and acidified by addition of concentrated hydrochloric acid. The solid product, so formed, was collected by filtration and crystallised from dioxane. 
Compound 2 a formed a yellow crystals, m.p. $245{ }^{\circ} \mathrm{C}$; yield $70 \%$ IR: $1620 \mathrm{~cm}^{-1}\left(\delta \mathrm{NH}_{2}\right)$ and abroad band $3200-3300(v \mathrm{NH})$.

$\mathrm{C}_{10} \mathrm{H}_{10} \mathrm{~N}_{6} \mathrm{~S}$

Calcd $\quad$ C $48.7 \quad$ H $4.06 \quad \mathrm{~S} 13.00$,

Found C 48.3 H 4.01 S 12.4.

When 2 a was refluxed for a short period with acetic acid and hydrochloric acid compound 3 a was formed in quantitative yield.

Compound 3a formed yellow crystals; m.p. $265{ }^{\circ} \mathrm{C}$; yield $80 \%$ IR: $1620 \sim 1650\left(\delta \mathrm{NH}_{2}\right.$ and $\left.\mathrm{CO}\right)$, 3300 and $3420 \mathrm{~cm}^{-1}\left(v \mathrm{NH}_{2}\right)$.

\section{$\mathrm{C}_{10} \mathrm{H}_{10} \mathrm{~N}_{5} \mathrm{ClSO}$ \\ Calcd C 42.3 H 3.5 S 11.3, \\ Found C 42.3 H 3.2 S 11.2.}

Compound $3 \mathrm{~b}$ could be prepared via treatment of 1b with thiourea under the same conditions and boiling the resulting reaction product for a short period with acetic acid and hydrochloric acid.

Compound 3 formed yellow crystals; m.p. $245^{\circ} \mathrm{C}$; yield $98 \%$.

$\begin{array}{llll}\mathrm{C}_{10} \mathrm{H}_{9} \mathrm{~N}_{5} \mathrm{Cl}_{2} \mathrm{SO} & & & \\ \text { Calcd } & \mathrm{C} 37.7 & \mathrm{H} 2.8 & \mathrm{~S} 10.0, \\ \text { Found } & \mathrm{C} 37.5 & \mathrm{H} 2.8 & \mathrm{~S} 10.0 .\end{array}$

\section{4-Amino-6-hydroxy-5-phenylhydrazono-2,5-} dihydropyrimidin-2-one-hydrochloride (4)

To a solution of sodium ethoxide (prepared from $5.0 \mathrm{~g}$ of sodium metal and $150 \mathrm{ml}$ of absolute ethanol), compound 1 a $(0.1$ mole $)$ and urea $(0.1$ mole) were added. The reaction mixture was refluxed for $30 \mathrm{~h}$ then evaporated in vacuo. The remaining product was dissolved in water and acidified by the addition of concentrated hydrochloric acid. The solid product, so formed, was collected by filtration and crystallized from acetic acid containing $1 \%$ concentrated hydrochloric acid.

Compound $\mathbf{4}$ formed yellow crystals: m.p. $>300{ }^{\circ} \mathrm{C}$; yield $70 \%$. IR: $1640 \sim 1660 \mathrm{~cm}^{-1}(\mathrm{CO}$ and $\left.\delta \mathrm{NH}_{2}\right) ; 1725 \mathrm{~cm}^{-1}(\mathrm{CO})$ and $2500 \sim 3340 \mathrm{~cm}^{-1}$ (chelated $\mathrm{OH}$ and $\mathrm{NH}$ groups).

\section{$\mathrm{C}_{10} \mathrm{H}_{10} \mathrm{~N}_{5} \mathrm{O}_{2} \mathrm{Cl}$ \\ Calcd C 44.8 H 3.7 N 26.1, \\ Found C 44.5 H 4.1 N 25.5.}

\section{4-Amino-aryl-3,5-dicyano-6-}

iminopyridazines $(\mathbf{5} \mathbf{a}, \mathbf{b})$

To a solution of $1 \mathrm{a}, \mathrm{e}(0.01 \mathrm{~mole})$ in pyridine $(30 \mathrm{ml})$ malononitrile $(0.7 \mathrm{~g})$ was added. The reaction mixture was refluxed for $10 \mathrm{~h}$ then cooled and poured into water. The solid product, so formed, was collected by filtration and crystallised from DMF.

Compound 5a formed brown crystals; m.p. $>300{ }^{\circ} \mathrm{C}$; yield $80 \%$. IR: $1630\left(\mathrm{C}=\mathrm{N}\right.$ and $\left.\delta \mathrm{NH}_{2}\right)$; $2180-2190 \mathrm{~cm}^{-1}$ (conjugated $\mathrm{CN}$ and $2900 \sim 3400$ (chelated $\mathrm{NH}$ vibrations).

\section{$\mathrm{C}_{12} \mathrm{H}_{8} \mathrm{~N}_{6}$ \\ Calcd C 61.0 H 3.3, \\ Found C 60.9 H 3.2.}

Compound 5 a was also obtained in $70 \%$ yield via cyclization of $\mathbf{6}$ (see latter) by refluxing in DMF for $10 \mathrm{~min}$ and on working up the reaction mixture.

Compound 5b formed brown crystals: m.p. $>300{ }^{\circ} \mathrm{C}$; yield $75 \%$. IR : $1630 \sim 1660(\mathrm{C}=\mathrm{N}$ and $\delta \mathrm{NH}_{2}$ ); 2200 and 2220 (two conjugated $\mathrm{CN}$ ) and $2900 \sim 3360$ (chelated $\mathrm{NH}$ vibration).

$\mathrm{C}_{12} \mathrm{H}_{7} \mathrm{~N}_{6} \mathrm{Cl}$

Calcd C 53.2 H 2.5,

Found C 53.0 H 2.6.

Compound 5e formed brown crystals; m.p. $>300{ }^{\circ} \mathrm{C}$; yield $86 \%$.

$\mathrm{C}_{13} \mathrm{H}_{10} \mathrm{~N}_{6}$

Calcd C 62.4 H 4.0,

Found C 62.4 H 4.6.

\section{2-Amino-1,1,3-tricyano-3-phenylhydrazono- propene $(\mathbf{6 a})$}

To a solution of (0.1 mole) 2-amino-1,1,3-tricyanopropene (prepared via dimerization of malononitrile as has been described in literature [15]) in ethanol $(100 \mathrm{ml}), 5.0 \mathrm{~g}$ of anhydrous sodium acetate was added. The solution was then treated with a solution of 0.1 mole of benzene diazonium chloride (prepared from 0.1 mole aniline and the appropriate quantities of hydrochloric acid and sodium nitrite. The reaction mixture was stirred for $1 \mathrm{~h}$ and the resulting solid product was collected by filteration and purified by washing with hot ethanol.

Compound $\mathbf{6}$ a formed brown crystals : m. p. above $300{ }^{\circ} \mathrm{C}$, yield $80 \%$. IR: $1600 \mathrm{~cm}^{-1} \quad(-\mathrm{N}=\mathrm{N}-)$, $1640 \mathrm{~cm}^{-1} \quad(>\mathrm{C}=\mathrm{C}<\mathrm{N}<)$ and 2220 (conjugated $\mathrm{CN})$.

$\mathrm{C}_{12} \mathrm{H}_{8} \mathrm{~N}_{6}$

$\begin{array}{llll}\text { Calcd } & \text { C 61.01 } & \text { H } 3.38 & \text { N 35.59, } \\ \text { Found } & \text { C 60.88 } & \text { H 3.34 } & \text { N 35.40. }\end{array}$

\section{1-Aryl-4-amino-3-cyano-1,6-dihydro-1,2,4-triazin- 6 -thione $(7 \mathrm{a}, \mathrm{b})$}

To a solution of benzoyl isothiocyanate (prepared from $7.5 \mathrm{~g}$ of ammonium thiocyanate and the appropriate quantitatively of benzoyl chloride as has been previously described) [9] in pyridine $100 \mathrm{ml}, 0.1$ mole of each of $1 \mathrm{a}, \mathrm{b}$ was added. The reaction mixture was refluxed for $24 \mathrm{~h}$, evaporated in vacuo the reaction mixture was then washed with water and the resulting solid product was collected by filtration and crystallised from pyridine.

Compound $\mathbf{7 a}$ formed brown crystals: m.p. $220{ }^{\circ} \mathrm{C}$; yield $70 \%$. IR: $1640 \sim 1660 \mathrm{~cm}^{-1}\left(\delta \mathrm{NH}_{2}\right)$ $2200 \mathrm{~cm}^{-1}$ (CN); $2500-3340 \mathrm{~cm}^{-1}$ (chelated $\mathrm{NH}$ vibrations). 


\section{$\mathrm{C}_{10} \mathrm{H}_{7} \mathrm{~N}_{5} \mathrm{~S}$ \\ Calcd C 52.4 H 3.1 S 13.9, \\ Found C 52.8 H 3.2 S 14.0.}

Compound $\mathbf{7 b}$ formed yellow crystals from $\mathrm{AcOH}$ and $\mathrm{HCl}$ mixture, m.p. $235^{\circ} \mathrm{C}$; yield $70 \%$.

\section{$\mathrm{C}_{10} \mathrm{H}_{6} \mathrm{~N}_{5} \mathrm{SCl}$ \\ Calcd C 45.4 H 2.2 S 12.1, \\ Found C 45.3 H 2.2 S 12.0.}

Compounds $\mathbf{7}$ a, b were also obtained in $80 \%$ yield when $\mathbf{1} \mathbf{a}, \mathbf{b}$ were treated with ethoxycarbonylisothiocyanate under similar conditions.

\section{1-Aryl-4-carboxyamido-3-cyano-6-trioxo-}

1,6-dihydro-1,2,4-triazine (8)

Compound 8 was prepared refluxed, 1e with equivalent quantity of benzoyl isothiocyanate and the reaction mixture was refluxed for $48 \mathrm{~h}$ then treated as has been described above.

Compound 8 formed yellow crystals: m.p. $>300{ }^{\circ} \mathrm{C}$; yield $70 \%$. IR: $1660 \mathrm{~cm}^{-1}$ (CO) and $3100 \mathrm{~cm}^{-1} \sim 3400 \mathrm{~cm}^{-1}$ (NH vibrations).

$$
\begin{array}{ccccc}
\mathrm{C}_{11} \mathrm{H}_{11} O \mathrm{~N}_{5} \mathrm{~S} & & & & \\
\text { Calcd } & \mathrm{C} 50.6 & \mathrm{H} 4.2 & \mathrm{~N} 26.8 & \mathrm{~S} 12.2 \text {, } \\
\text { Found } & \mathrm{C} 51.0 & \mathrm{H} \mathrm{4.2} & \mathrm{N} 26.2 & \mathrm{~S} 11.9 .
\end{array}
$$

\section{5-Amino-3-hydroxy-4-phenylazoisoxazole (11)}

A solution of 1 a $(0.1$ mole $)$ in ethanol $(150 \mathrm{ml})$ was treated with hydroxylamine hydrochloride (0.1 mole) and sodium carbonate ( 0.1 equivalent). The reaction mixture was refluxed for $3 \mathrm{~h}$, then left to cool. The solid product, formed on standing, was collected by filtration, washed everal times with water and then crystallised from ethanol.

Compound 6 formed yellow crystals : m.p. $245^{\circ} \mathrm{C}$; yield $80 \%$.

$$
\begin{array}{cccc}
\mathrm{C}_{9} \mathrm{H}_{8} \mathrm{~N}_{4} \mathrm{O}_{2} & & & \\
\text { Calcd } & \text { C 52.9 } & \text { H 3.9 } & \text { N 27.4, } \\
\text { Found } & \text { C 52.5 } & \text { H 3.8 } & \text { N 26.9. }
\end{array}
$$

\section{$N$-Methyl-phenylazomalononitrile (13a)}

To a solution of $1.7 \mathrm{~g}$ ( 0.01 mole) of phenylazomalononitrile in $50 \mathrm{ml}$ acetone, was added $1.4 \mathrm{~g}$ (0.01 mole) methyl iodide and $2 \mathrm{~g}$ of anhydrous potassium carbonate. The reaction mixture was refluxed for $90 \mathrm{~min}$, then evaporated in vacuo. The solid product so formed was collected by filtration and crystallised from methanol.

Compound 13a formed yellow crystals, m.p. $100{ }^{\circ} \mathrm{C}$; yield $80 \%$. IR: 2200 and $2220 \mathrm{~cm}^{-1}$ (two $\mathrm{CN}), 1590 \mathrm{~cm}^{-1}(\delta \mathrm{C}=\mathrm{N})$.

$$
\begin{array}{ccc}
\mathrm{C}_{10} \mathrm{H}_{8} \mathrm{~N}_{4} & & \\
\text { Calcd } & \mathrm{C} 65.2 & \mathrm{H} \mathrm{4.3}, \\
\text { Found } & \mathrm{C} 65.1 & \mathrm{H} \mathrm{4.6.}
\end{array}
$$

This compound was found identical with authentic speciment [9].

\section{$N$-Ethylarylazomalononitrile $(\mathbf{1 3 b}, \mathbf{c})$}

Compounds 13 b, e were obtained in $80 \%$ yield via treatment of $\mathbf{2} \mathbf{a}, \mathbf{b}$ with equivalent quantity of ethyl iodine utilising the experiment conditions described above and refluxing the reaction mixture $15 \mathrm{~h}$.

Compound $13 \mathrm{~b}$ formed colourless crystals: m.p. $65{ }^{\circ} \mathrm{C}$. IR: $2620(\mathrm{C}=\mathrm{N}) ; 2200$ and $2210 \mathrm{~cm}^{-1}$ (two conjugated $\mathrm{CN}$ ).

$\mathrm{C}_{11} \mathrm{H}_{10} \mathrm{~N}_{4}$

$\begin{array}{llll}\text { Calcd } & \text { C } 66.6 & \text { H } 5.05 & \text { N } 28.2,\end{array}$

Compound $13 \mathrm{c}$ formed colourless crystals; m.p. $65{ }^{\circ} \mathrm{C}$. IR : $1620 \mathrm{~cm}^{-1}(\mathrm{C}=\mathrm{N}) ; 2200$ and $2220 \mathrm{~cm}^{-1}$ (two conjugated $\mathrm{CN}$ ).

$\mathrm{C}_{11} \mathrm{H}_{9} \mathrm{~N}_{4} \mathrm{Cl}$

Calcd C 56.7 H 3.8 N 24.1 Cl 15.2,

Found C 56.5 H 3.7 N 23.9 Cl 15.1.

\section{$N$-Alkylarylazocyanoacetamidrazone (14a-c)}

A solution of $1.8 \mathrm{~g}(0.01$ mole $)$ of $13 \mathrm{a}-\mathbf{c}$, in $50 \mathrm{ml}$ ethanol, was treated with $0.5 \mathrm{~g}$ ( 0.01 mole) of hydrazine hydrate $(98 \%)$. The reaction mixture was refluxed for $90 \mathrm{~min}$, then evaporated in vacuo. The solid product so formed was collected by filtration and crystallised from ethanol.

Compound 14a formed yellow needles, m.p. $140{ }^{\circ} \mathrm{C}$, yield $75 \%$. IR: 3400 and $3340 \mathrm{~cm}^{-1}\left(\sigma \mathrm{NH}_{2}\right.$ and $\mathrm{NH}), 2200 \mathrm{~cm}^{-1}(\delta \mathrm{CN}), 1650 \mathrm{~cm}^{-1}(\mathrm{C}=\mathrm{N})$, and $1600 \mathrm{~cm}^{-1}\left(\delta \mathrm{NH}_{2}\right)$.

$\mathrm{C}_{11} \mathrm{H}_{14} \mathrm{~N}_{6}$

Calcd C 57.3 H 6.1 N 36.6,

Found C 57.2 H 6.1 N 36.2.

Compound $14 \mathrm{~b}$ formed brown crystals; m.p. $85^{\circ} \mathrm{C}$; yield $70 \%$. IR : $1610 \mathrm{~cm}^{-1}(\mathrm{C}=\mathrm{N}), 1670 \mathrm{~cm}^{-1}$ $\left(\delta \mathrm{NH}_{2}\right) ; 2210(\mathrm{CN}) 3350$ and $3460 \mathrm{~cm}^{-1}\left(\sigma \mathrm{NH}_{2}\right)$.

$\mathrm{C}_{15} \mathrm{H}_{14} \mathrm{~N}_{6}$

\section{Calcd C 64.7 H 5.0,}

Found C 64.5 H 5.1.

Compound 14e formed brown crystals; m.p. $95^{\circ} \mathrm{C}$; yield $70 \%$.

$$
\begin{aligned}
C_{11} H_{13} N_{6} C l & \\
\text { Calcd } & \text { Cl 13.4, } \\
\text { Found } & \text { Cl 13.0. }
\end{aligned}
$$

\section{Reaction of $\mathbf{1 4}$ a with acetic acid}

A solution of $1.7 \mathrm{~g}(0.01$ mole $)$ of $14 \mathrm{a}$ in $50 \mathrm{ml}$ acetic acid was refluxed for $30 \mathrm{~min}$. The solvent was then evaluated in vacuo. The remaining product was triturated with water and the solid product so formed, was collected by filtration. Repeated crystallisation from methanol affected analytically pure sample. 
Compound 10 formed greenish yellow crystals, m.p. $115^{\circ} \mathrm{C}$, yield $70 \%$. IR: broad band at $3450 \mathrm{~cm}^{-1} \quad(\delta \mathrm{NH}), \quad 2200 \mathrm{~cm}^{-1} \quad(\delta \mathrm{CN}), \quad 1600 \mathrm{~cm}^{-1}$ $(v \mathrm{NH})$.
$\mathrm{C}_{20} \mathrm{H}_{17} \mathrm{~N}_{9}$

Calcd $\quad$ C $62.6 \quad \mathrm{H} 4.4 \quad \mathrm{~N} 32.8$, Found $\mathrm{C} 62.8$ H 4.3 N 32.5.
[1] W. Lax, J. Prakt. Chem. 63, 1 (1901).

[2] P. G. Heytler and W. W. Prichard, Biochem. Biophys. Res. Commun. 1, 272 (1962).

[3] B. Fiehn and G. Tollin, Arch. Biochem. Biophys. 121,169 (1969).

[4] E. S. Bamberger, G. G. Black, C. A. Fewson, and M. Gibbs, Plant Physiol. 38, 483 (1963).

[5] J. F. Ferris, Biological function and formation of the cyano-group, in Z. Rappaport (ed.): The chemistry of cyano group, Chapt. 12, Z. p. 735, Interscience, New York 1970.

[6] M. H. Elnagdi and Hussein Mahmoud Fahmy, J. Electroanal. Chem. 84, 149 (1977).

[7] M. H. Elnagdi, Tetrahedron 30, 2791 (1974).

[8] Mohamed H. Elnagdi and M. M. M. Sallam, Helv. Chim. Acta 58, 1944 (1975).

[9] M. H. Elnagdi and S. O. Abd Allah, J. Prakt. Chem. 315, 1009 (1973).
[10] M. H. Elnagdi and Ezzat M. Kandeel, J. Heterocyc. Chem. 14, 155 (1977).

[11] Edward C. Taylor and Alexander McKillop, The Chemistry of Cyclic Enaminonitriles, Advances in Organic Chemistry, Vol. 7 (1970).

[12] S. Baldwin, J. Org. Chem. 26, 3288 (1961).

[13] While performing this work the reaction of $\mathbf{1}$ with aryl and alkyl isothiocyanates has been published by P. Wenternitz, Helv. Chim. Acta 61, 1175 (1978) to yield 5-imino-6-cyano-1,2,4triazine derivatives.

[14] M. H. Elnagdi, M. R. H. Elmoghayar, E. A. A. Hafez, D. H. Fleita, and S. M. Fahmy, J. Org. Chem. 41, 3781 (1976).

[15] E. C. Taylor and K. S. Hartke, J. Am. Chem. Soc. 81, 2452 (1959). 